\title{
Prediction equations for digestible and metabolizable energy concentrations in feed ingredients and diets for pigs based on chemical composition
}

\author{
Jung Yeol Sung ${ }^{1}$ and Beob Gyun Kim ${ }^{1, *}$
}

\section{* Corresponding Author: Beob Gyun Kim Tel: +82-2-2049-6255, Fax: +82-2-455-1044, E-mail: bgkim@konkuk.ac.kr}

${ }^{1}$ Department of Animal Science and Technology, Konkuk University, Seoul 05029, Korea

ORCID

Jung Yeol Sung

https://orcid.org/0000-0001-9214-2724

Beob Gyun Kim

https://orcid.org/0000-0003-2097-717X

Submitted May 2, 2020; Revised Jun 3, 2020; Accepted Jul 13, 2020
Objective: The objectives were to develop prediction equations for digestible energy (DE) and metabolizable energy (ME) of feed ingredients and diets for pigs based on chemical composition and to evaluate the accuracy of the equations using in vivo data.

Methods: A total of 734 data points from 81 experiments were employed to develop prediction equations for $\mathrm{DE}$ and ME in feed ingredients and diets. The CORR procedure of SAS was used to determine correlation coefficients between chemical components and energy concentrations and the REG procedure was used to generate prediction equations. Developed equations were tested for the accuracy according to the regression analysis using in vivo data.

Results: The DE and ME in feed ingredients and diets were most negatively correlated with acid detergent fiber or neutral detergent fiber (NDF; $r=-0.46$ to $r=-0.67 ; p<0.05$ ). Three prediction equations for feed ingredients reflected in vivo data well as follows: $\mathrm{DE}=728+$ $0.76 \times$ gross energy $(\mathrm{GE})-25.18 \times \mathrm{NDF}\left(\mathrm{R}^{2}=0.64\right) ; \mathrm{ME}=965+0.66 \times \mathrm{GE}-24.62 \times \mathrm{NDF}\left(\mathrm{R}^{2}\right.$ $=0.60) ; \mathrm{ME}=1,133+0.65 \times \mathrm{GE}-29.05 \times \mathrm{ash}-23.17 \times \mathrm{NDF}\left(\mathrm{R}^{2}=0.67\right)$.

Conclusion: In conclusion, the equations suggested in the current study would predict energy concentration in feed ingredients and diets.

Keywords: Digestible Energy; Metabolizable Energy; Prediction Equation; Swine

\section{INTRODUCTION}

Energy is known to be one of the most expensive nutritional components in animal feeds. Available energy of feeds can be partitioned into digestible energy (DE), metabolizable energy (ME), and net energy subtracting energy losses from gross energy (GE) [1]. However, net energy is less widely used compared with DE and ME due to difficulties of its determination and relatively large variations [2]. To obtain energy concentrations of feed ingredients and diets, metabolism experiments are required to collect feces and urine through restriction of physical activity of animals. However, as in vivo experiments are time-consuming and costly, prediction equations based on chemical components have been regarded as an alternative method for obtaining DE and ME of feeds [3].

Prediction equations for $\mathrm{DE}$ or $\mathrm{ME}$ for pigs have been developed for specific feed ingredients [4-6] and diets [3,7,8]. However, available equations for predicting energy concentrations in the literature are not applicable or risky in many cases. For example, some equations can be applied only to specific ingredients and others have a relatively narrow range of dietary chemical compositions. Inappropriate uses of these equations are susceptible to extrapolation bias $[9,10]$. To solve these problems, Choi et al [11] developed equations for $\mathrm{DE}$ in feed ingredients and diets for growing pigs and these equations were shown to 
be more accurate than previously published equations. However, Choi et al [11] provided equations only for DE but not ME. Therefore, the objectives of this study were to develop widely applicable prediction equations for DE and ME in feed ingredients and diets for pigs based on chemical components and to validate these equations using data from in vivo experiments.

\section{MATERIALS AND METHODS}

\section{Data collection}

A total of 734 data points from 81 studies that determined DE or ME were employed to develop equations for energy concentrations in feed ingredients and diets for pigs. The database consisted of chemical compositions and energy concentrations of feed ingredients and diets used in the experiments. Energy contents were expressed in $\mathrm{kcal} / \mathrm{kg}$ dry matter (DM) and other variables were in \% DM. When chemical components of feed ingredients or diets were not provided in a paper, chemical components were calculated by multiplying the inclusion rate of each ingredient by values provided in Sauvant et al [12] and NRC [1].

\section{Statistical analysis}

Correlation coefficients between chemical components and energy concentrations were determined by the CORR procedure of SAS (SAS Inst. Inc., Cary, NC, USA). Prediction equations for DE and ME were developed by the REG procedure. A coefficient of determination was an indicator to define the best fit equations.

The alpha level used for determining statistical significance was 0.05 . The accuracy of prediction equations for energy concentrations was assessed by regressing the determined values of data from in vivo experiments [13-18] minus the predicted values for energy concentrations on the predicted values centered to the mean [19]. These data had not been used in developing prediction equations. To validate prediction equations for energy concentrations, only data corresponding to the range of chemical components used for equations in the current study were employed.

\section{RESULTS AND DISCUSSION}

Both of index method and total collection method are used for determining DE in feed ingredients and diets in pigs. In the present work, the experiments that used the index method were excluded. The reason for excluding data from the index method was that the indigestible index method may potentially underestimate nutrient digestibility due to low index recovery [20].

Feed ingredients had a wider range and greater variations of chemical components compared with diets (Table 1). The range of chemical composition of feed ingredients in the current study was wider than that of the previous studies $[6,8,11]$, which is desirable for establishing prediction equations. The range of dietary chemical components of diets in the present work was wider than that in the work by Noblet and Perez [3], but maximum ash, crude protein, and neutral detergent fiber (NDF) contents were less than those of previous studies $[7,8]$.

The DE and ME in feed ingredients and diets were correlated most negatively with acid detergent fiber $(\mathrm{ADF})$ and NDF representing dietary fiber $(r=-0.46$ to $r=-0.67$; Tables $2,3)$. The negative correlations between dietary fibers and available energy are in good agreement with previous studies where dietary fiber was the best predictor $[3,7,8,11]$. This is because dietary fiber decreases energy digestibility of other nutrients, and the digestibility of fiber itself is relatively less compared with starch, proteins, and lipids [7]. Dietary fiber can be categorized into crude fiber, ADF, NDF, total dietary fiber (TDF), insoluble dietary fiber, and soluble dietary fiber based on fiber analysis procedures [1]. In some previous studies, TDF was the most accurate independent variable to predict $\mathrm{DE}$ in corn byproducts among various dietary fibers $[21,22]$. As TDF includes $\beta$-glucans unlike other dietary fibers, theoretically, TDF provides an accurate estimate

Table 1. The variability of chemical components in feed ingredients and diets in the database (dry matter basis)

\begin{tabular}{|c|c|c|c|c|c|c|c|c|c|c|}
\hline \multirow{2}{*}{ Item } & \multicolumn{5}{|c|}{ Feed ingredients } & \multicolumn{5}{|c|}{ Diets } \\
\hline & $\mathbf{n}$ & Mean & Min. & Max. & SD & $\mathbf{n}$ & Mean & Min. & Max. & SD \\
\hline GE (kcal/kg) & 423 & 4,794 & 3,317 & 6,349 & 491 & 278 & 4,489 & 4,025 & 5,319 & 211 \\
\hline ME (kcal/kg) & 437 & 3,497 & 1,569 & 5,989 & 606 & 264 & 3,655 & 2,893 & 4,321 & 279 \\
\hline EE (\%) & 397 & 5.8 & 0 & 27.5 & 4.9 & 215 & 4.2 & 0.6 & 11.8 & 2.2 \\
\hline CP (\%) & 450 & 32.9 & 2.0 & 101.4 & 20.8 & 282 & 18.6 & 7.3 & 30.1 & 5.2 \\
\hline Ash (\%) & 416 & 7.0 & 0.2 & 46.2 & 7.1 & 177 & 5.3 & 2.3 & 11.7 & 1.5 \\
\hline
\end{tabular}

SD, standard deviation; GE, gross energy; DE, digestible energy; ME, metabolizable energy; EE, ether extract; CP, crude protein; NDF, neutral detergent fiber; $A D F$, acid detergent fiber. 
Table 2. Correlation coefficients between energy concentrations and chemical components in feed ingredients

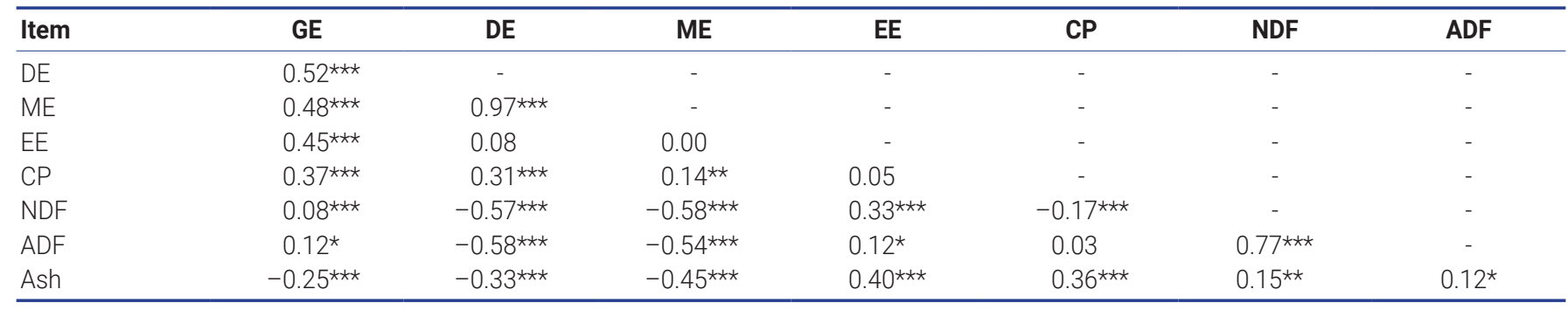

$\mathrm{GE}$, gross energy; $\mathrm{DE}$, digestible energy; $\mathrm{ME}$, metabolizable energy; $E \mathrm{E}$, ether extract; $\mathrm{CP}$, crude protein; NDF, neutral detergent fiber; $A D F$, acid detergent fiber. ${ }^{*} p<0.05,{ }^{*} p<0.01$, and $* \star * p<0.001$.

Table 3. Correlation coefficients between energy concentrations and chemical components in diets

\begin{tabular}{lllccccc}
\hline Item & GE & DE & ME & EE & CP & NDF & ADF \\
\hline DE & $0.37^{\star \star \star}$ & - & - & - & - & - \\
ME & $0.20^{\star \star \star}$ & $0.98^{\star \star \star}$ & - & - & - & - \\
EE & $0.61^{\star \star \star}$ & 0.12 & 0.05 & - & - & - \\
CP & $0.29^{\star \star \star}$ & -0.01 & -0.11 & 0.03 & - & - & - \\
NDF & $0.19^{\star \star}$ & $-0.46^{\star \star \star}$ & $-0.52^{\star \star \star}$ & $0.30^{\star \star \star}$ & 0.09 & - & - \\
ADF & $0.16^{\star}$ & $-0.63^{\star \star \star}$ & $-0.67 \star \star \star$ & $0.27^{\star \star \star}$ & 0.12 & $0.77^{\star \star \star}$ \\
Ash & $0.27^{\star \star \star}$ & -0.12 & $-0.31^{\star \star \star}$ & $0.24^{\star \star}$ & $0.28^{\star \star \star}$ & $0.22^{\star \star}$ & $0.30^{\star \star \star}$ \\
\hline
\end{tabular}

GE, gross energy; DE, digestible energy; ME, metabolizable energy; EE, ether extract; CP, crude protein; NDF, neutral detergent fiber; ADF, acid detergent fiber. $\star p<0.05, * \star p<0.01$, and $* \star \star p<0.001$.

of dietary fiber [1]. However, a recent meta-analysis study indicated that dietary fiber analyzed by detergent fiber procedure showed a greater accuracy in predicting DE in feed ingredients and diets compared with TDF, insoluble dietary fiber, and soluble dietary fiber [11]. For this reason, the NDF and ADF were used to represent dietary fiber when developing equations in the current study.

Ash was also regarded as a potential independent variable for estimating DE and ME in feed ingredients and diets in the present work. Generally, energy concentrations in ingredients and diets decrease as ash concentration increases due to the lack of GE in ash [3]. In the current study, ash was negatively correlated with GE $(r=-0.25), \mathrm{DE}(\mathrm{r}=-0.33)$, and $\mathrm{ME}$ $(r=-0.45)$ in feed ingredients and was used for predicting DE and ME in several equations (Eq. 3, 5, 7, 8, and 12 to 17). In contrast to feed ingredients, ash was not included in the equations for predicting DE and ME in diets, which is likely due to the relatively narrow range of ash contents in diets (2.3\% to $11.7 \%)$ compared with feed ingredients $(0.2 \%$ to $46.2 \%)$.

Based on coefficients of determination, prediction equations for DE and ME in feed ingredients and diets were developed (Tables 4,5). Equations with less than 0.5 of coefficient of determination were excluded. Some variables were highly correlated each other resulting in a decrease of the validity of regression coefficients as predictors [7]. For this reason, $\mathrm{ADF}$ and NDF were not included in the equation as independent variables as well as ether extract and GE.
In vivo experiments for testing the accuracy of the present equations were conducted in our laboratory and experimental conditions were kept constant among experiments (e.g., chemical analysis, environment and facilities, experimental procedures, and genetic strains of pigs). The $\mathrm{DE}$ or ME obtained from in vivo experiments was plotted against the $\mathrm{DE}$ or ME calculated using the equations developed in the present work. The intercept and slope generated by mean-centered regression representing a mean bias and linear bias, respectively, can be used as indicators of accuracy [23]. The mean bias and linear bias represent the difference between the average of measured and predicted energy values and the consistency of prediction error across the range of data, respectively. Based on the regression analyses, the slope and intercept were not different from 0 when validating Eq. 2, 11, and 12 (Tables 4, 5), which indicates that these equations accurately estimates in vivo $\mathrm{DE}$ and $\mathrm{ME}$ data employed in the present work.

Compared with prediction models for DE or ME in the literature, the present equations showed lower coefficients of determination and greater root mean squares of error. One possible reason is that experiments used to establish equations in the current study were conducted by various experimental stations. Experimental conditions may differ among institutions and these factors may cause variations. Particularly for chemical analysis, statistically significant difference may occur among analyzed values even though each station follows the same methods of chemical analysis [24]. In contrast to the 
Table 4. Prediction equations for energy concentrations in feed ingredients and validation of equations (1),2) $^{2}$

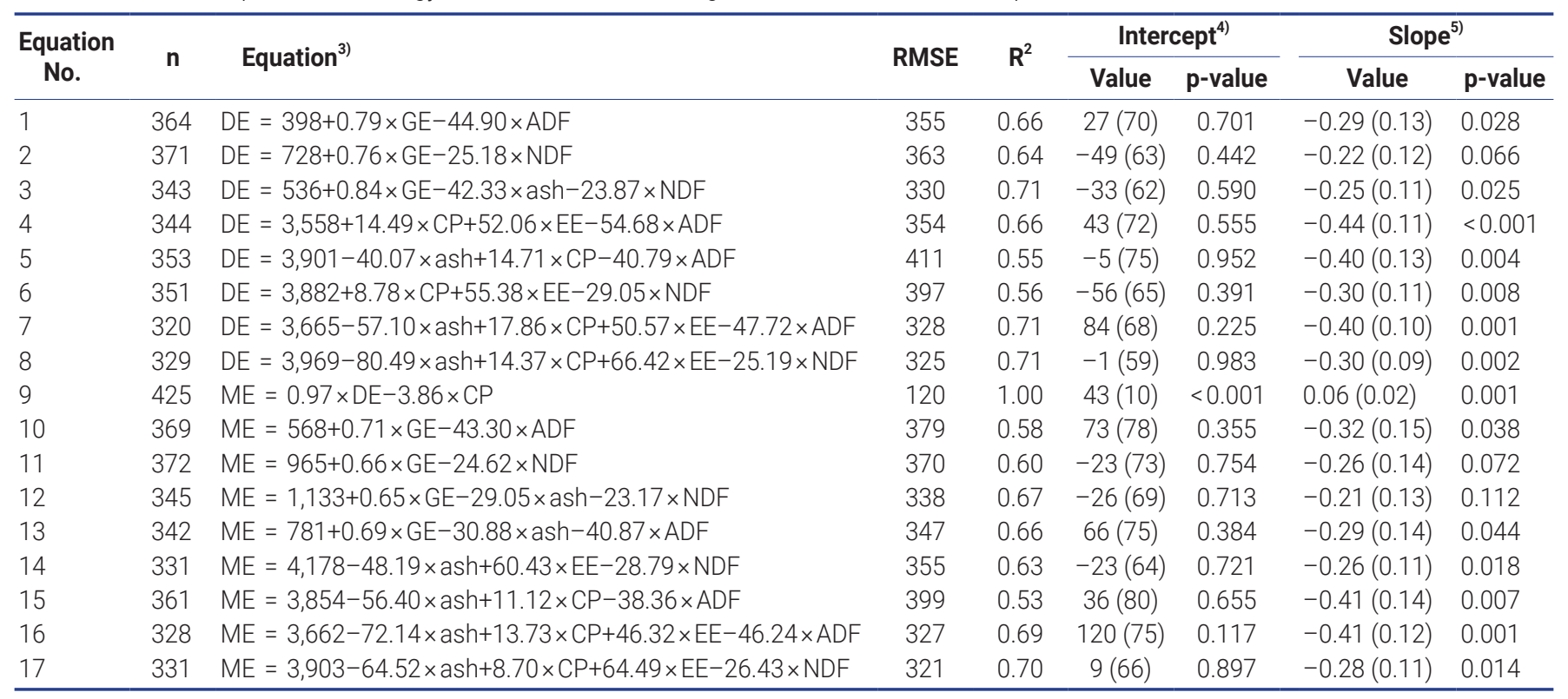

RMSE, root mean square of error; DE, digestible energy; GE, gross energy; ADF, acid detergent fiber; NDF, neutral detergent fiber; CP, crude protein; $E E$, ether extract; ME, metabolizable energy.

1) Thirty nine in vivo data points were employed to validate prediction equations for energy concentrations in feed ingredients.

2) Values in parentheses are standard error.

3) Energy concentrations and chemical composition are expressed as $\mathrm{kcal} / \mathrm{kg}$ dry matter and \% dry matter, respectively.

4) The intercept represents the mean bias.

5) The slope represents the linear bias.

current study, factors aforementioned were relatively controlled in previous modeling studies because most of metabolism experiments and chemical analysis were conducted in their own laboratories $[3,6,25]$. Another possible reason is that most of data used for establishing equations in the current study were derived from energy evaluation of feed ingredients. To evaluate available energy concentration in a feed ingredient precisely, the proportion of a target feedstuff is high which leads to an impractical diet formulation. In contrast, most diets fed to pigs to derive equations in previous studies $[3,26]$ were corn- or wheat-based diets where the proportion of non-conventional feed ingredients was low. In addition, while previous equations for feed ingredients were applicable for specific feed ingredients such as animal byproduct, corn coproduct, and wheat $[6,21,27]$, the equations developed in the present work were established based on various types of feed ingredients.

Despite these problems, the equations suggested in the current study are meaningful because most of data used for developing equations were derived from the recent studies. A great number of recent observations employed in the present work compared with previous studies should also be noted $[3,7,25]$. Furthermore, independent variables in equations consisted of commonly analyzed components in

Table 5. Prediction equations for energy concentrations in diets and validation of equations ${ }^{1), 2)}$

\begin{tabular}{|c|c|c|c|c|c|c|c|c|}
\hline \multirow{2}{*}{$\begin{array}{c}\text { Equation } \\
\text { No. }\end{array}$} & \multirow{2}{*}{$\mathbf{n}$} & \multirow{2}{*}{ Equation $^{3)}$} & \multirow{2}{*}{ RMSE } & \multirow{2}{*}{$\mathbf{R}^{2}$} & \multicolumn{2}{|c|}{ Intercept $^{4)}$} & \multicolumn{2}{|c|}{ Slope $^{5)}$} \\
\hline & & & & & Value & p-value & Value & p-value \\
\hline 18 & 232 & $\mathrm{DE}=965+0.72 \times \mathrm{GE}-66.40 \times \mathrm{ADF}$ & 187 & 0.61 & $-13(28)$ & 0.646 & $-0.70(0.11)$ & $<0.001$ \\
\hline 20 & 228 & $\mathrm{ME}=1,521+0.56 \times \mathrm{GE}-65.30 \times \mathrm{ADF}$ & 184 & 0.59 & $21(29)$ & 0.470 & $-0.71(0.11)$ & $<0.001$ \\
\hline 21 & 185 & $\mathrm{ME}=3,847+38.69 \times \mathrm{EE}-67.24 \times \mathrm{ADF}$ & 181 & 0.57 & $41(30)$ & 0.174 & $-0.77(0.11)$ & $<0.001$ \\
\hline 22 & 185 & $\mathrm{ME}=3,741+5.75 \times \mathrm{CP}+39.84 \times \mathrm{EE}-68.86 \times \mathrm{ADF}$ & 179 & 0.58 & $63(29)$ & 0.041 & $-0.76(0.10)$ & $<0.001$ \\
\hline
\end{tabular}

RMSE, root mean square of error; DE, digestible energy; GE, gross energy; ADF, acid detergent fiber; ME, metabolizable energy; $C P$, crude protein; $E E$, ether extract.

1) Thirty two in vivo data points were employed to validate prediction equations for energy concentrations in feed ingredients.

2) Values in parentheses are standard error.

3) Energy concentrations and chemical composition are expressed as $\mathrm{kcal} / \mathrm{kg}$ dry matter and \% dry matter, respectively.

4) The intercept represents the mean bias.

5) The slope represents the linear bias. 
laboratories and equations were based on various combinations of chemical components.

\section{CONCLUSION}

Based on chemical compositions, energy concentrations in feed ingredients and diets can be fairly accurately estimated using the prediction equations proposed in this study. Further studies are warranted to develop prediction equations for net energy.

\section{CONFLICT OF INTEREST}

We certify that there is no conflict of interest with any financial organization regarding the material discussed in the manuscript.

\section{REFERENCES}

1. NRC. Nutrient Requirements of Swine. 11th ed. Washington, DC, USA: National Academies Press; 2012.

2. Kil DY, Kim BG, Stein HH. Feed energy evaluation for growing pigs. Asian-Australas J Anim Sci 2013;26:1205-17. https:// doi.org/10.5713/ajas.2013.r.02

3. Noblet J, Perez JM. Prediction of digestibility of nutrients and energy values of pig diets from chemical analysis. J Anim Sci 1993;71:3389-98. https://doi.org/10.2527/1993.71123389x

4. Adedokun SA, Adeola O. Metabolizable energy value of meat and bone meal for pigs. J Anim Sci 2005;83:2519-26. https:// doi.org/10.2527/2005.83112519x

5. Pedersen C, Boersma MG, Stein HH. Digestibility of energy and phosphorus in ten samples of distillers dried grains with solubles fed to growing pigs. J Anim Sci 2007;85:1168-76. https://doi.org/10.2527/jas.2006-252

6. Kerr BJ, Jha R, Urriola PE, Shurson GC. Nutrient composition, digestible and metabolizable energy content, and prediction of energy for animal protein byproducts in finishing pig diets. J Anim Sci 2017;95:2614-26. https://doi.org/ 10.2527/jas.2016.1165

7. Just A, Jørgensen H, Fernández JA. Prediction of metabolizable energy for pigs on the basis of crude nutrients in the feeds. Livest Prod Sci 1984;11:105-28. https://doi.org/10.1016/03016226(84)90012-5

8. Bulang M, Rodehutscord M. Development of equations for predicting metabolisable energy concentrations in compound feeds for pigs. Arch Anim Nutr 2009;63:442-54. https://doi. org/10.1080/17450390903217317

9. Noblet J, Jaguelin-Peyraud Y. Prediction of digestibility of organic matter and energy in the growing pig from an in vitro method. Anim Feed Sci Technol 2007;134:211-22. https:// doi.org/10.1016/j.anifeedsci.2006.07.008

10. Park CS, Son AR, Kim BG. Prediction of gross energy and digestible energy in copra meal, palm kernel meal, and cassava root fed to pigs. J Anim Sci 2012;90:221-3. https://doi.org/10. 2527/jas.53954

11. Choi H, Sung JY, Kim BG. Neutral detergent fiber rather than other dietary fiber types as an independent variable increases the accuracy of prediction equation for digestible energy in feeds for growing pigs. Asian-Australas J Anim Sci 2020;33:615-22. https://doi.org/10.5713/ajas.19.0103

12.Sauvant D, Perez JM, Tran G. Tables of composition and nutritional value of feed materials: pigs, poultry, cattle, sheep, goats, rabbits, horses and fish. 2nd ed. Wageningen, Netherlands: Wageningen Academic Publishers; 2004.

13.Son AR, Ji SY, Kim BG. Digestible and metabolizable energy concentrations in copra meal, palm kernel meal, and cassava root fed to growing pigs. J Anim Sci 2012;90:140-2. https:// doi.org/10.2527/jas.53822

14. Kwon WB, Kim BG. Effects of supplemental beta-mannanase on digestible energy and metabolizable energy contents of copra expellers and palm kernel expellers fed to pigs. AsianAustralas J Anim Sci 2015;28:1014-9. https://doi.org/10.5713/ ajas. 15.0275

15.Park CS, Son AR, Kil DY, Kim BG. Digestible and metabolizable energy in corn grains from different origins for growing pigs. Anim Sci J 2015;86:415-21. https://doi.org/10.1111/ asj. 12315

16.Son AR, Park CS, Kim BG. Determination and prediction of digestible and metabolizable energy concentrations in byproduct feed ingredients fed to growing pigs. Asian-Australas J Anim Sci 2017;30:546-53. https://doi.org/10.5713/ajas.16. 0607

17.Jo H, Kim BG. A high correlation between conventional and mini pigs in feed energy utilization. J Anim Sci 2018;96(Suppl 3):75. https://doi.org/10.1093/jas/sky404.165

18.Son AR, Kim BG. Energy concentration and phosphorus digestibility in single-cell protein and fish meal fed to growing pigs. J Anim Sci 2016;94:328-31. https://doi.org/10.2527/jas. 2015-9798

19. Kim BG, Kil DY, Zhang Y, Stein HH. Concentrations of analyzed or reactive lysine, but not crude protein, may predict the concentration of digestible lysine in distillers dried grains with solubles fed to pigs. J Anim Sci 2012;90:3798-808. https:// doi.org/10.2527/jas.2011-4692

20.Zhang F, Adeola O. Techniques for evaluating digestibility of energy, amino acids, phosphorus, and calcium in feed ingredients for pigs. Anim Nutr 2017;3:344-52. https://doi.org/ 10.1016/j.aninu.2017.06.008

21. Anderson PV, Kerr BJ, Weber TE, Ziemer CJ, Shurson GC. Determination and prediction of digestible and metabolizable energy from chemical analysis of corn coproducts fed to finishing pigs. J Anim Sci 2012;90:1242-54. https://doi.org/10.2527/ jas.2010-3605

22.Kerr BJ, Dozier WA, III, Shurson GC. Effects of reduced-oil 
corn distillers dried grains with solubles composition on digestible and metabolizable energy value and prediction in growing pigs. J Anim Sci 2013;91:3231-43. https://doi.org/10. 2527/jas.2013-6252

23. Sung JY, Kim BG. Prediction models for apparent and standardized total tract digestible phosphorus in swine diets. Anim Feed Sci Technol 2019;255:114224. https://doi.org/10. 1016/j.anifeedsci.2019.114224

24. Cromwell GL, Brendemuhl JH, Chiba LI, et al. Variability in mixing efficiency and laboratory analyses of a common diet mixed at 25 experiment stations. J Anim Sci 2003;81:48491. https://doi.org/10.2527/2003.812484x

25. Morgan CA, Whittemore CT, Phillips P, Crooks P. The pre- diction of the energy value of compounded pig foods from chemical analysis. Anim Feed Sci Technol 1987;17:81-107. https://doi.org/10.1016/0377-8401(87)90007-1

26. Moughan PJ, Dong GZ, Pearson G, Wilkinson BHP. Protein quality in blood meal: II. The effect of processing on in vivo nitrogen digestibility in rats, protein solubility and FDNBavailable lysine. Anim Feed Sci Technol 1999;79:309-20. https://doi.org/10.1016/S0377-8401(99)00028-0

27.Zijlstra RT, de Lange CFM, Patience JF. Nutritional value of wheat for growing pigs: chemical composition and digestible energy content. Can J Anim Sci 1999;79:187-94. https://doi. org/10.4141/A98-103 